\title{
Production of Polyhydroxyalkanoates from Industrial Food Wastes
}

\author{
Sergey M. SHISHLYANNIKOV ${ }^{1^{*}}$ and Veniamin Yu. SITNOV ${ }^{1}$ \\ ${ }^{1}$ All-Russian Research Institute for Food Additives - Branch of Federal Scientific Center for Food Systems \\ of Russian Academy of Sciences named after V.M. Gorbatov, St. Petersburg, Russian Federation \\ *Correspondence: sershilin@gmail.com
}

\begin{abstract}
Intensive research on microbial synthesis biopolymers such as polyhydroxyalkanoates (PHA) and their applications in the field of molecular biology, biochemistry, microbiology, engineering, polymer chemistry, as well as in the medical field has been conducted since the 70s of the 20th century. Nowadays dozens of commercial companies and enterprises have been created that are involved in scientific developments in the field of biosynthesis and large-scale production of PHA. The production and use of PHA connected with many areas of industry. These biopolymers are used in the production of environmentally friendly bioplastics, highly pure chemical compounds, materials for implants, drugs and biofuels. One of the acute problems of the widespread industrial production of PHA is the cost of carbon substrates, which is estimated at $28-50 \%$ of the total production process. Waste from food production is the main candidate for an inexpensive source of carbon for the growth of microorganisms producers of PHA. Another important factor associated with the disposal of food waste is the energy spent on the production, processing and transportation of waste. If alternative technologies have been developed to transform food waste into value-added products, then energy is essentially converted into useful products. The conversion of food waste into tangible bio-products has attracted much attention due to the creation of technologies for the production of a wide range of value-added products. The main goal of this review is to summarize the current state of PHA production from food waste using microorganisms.
\end{abstract}

Keywords: biopolymers, food waste, bioprocessing, polyhydroxyalkanoates, biodegradation.

\section{Introduction}

Polyhydroxyalkanoates (PHA) are a family of biopolyesters produced by many bacteria as a source of intracellular carbon and energy storage. Also, intracellular PHA promotes bacterial resistance to stress factors that allows them to endure unfavorable conditions $[1$, p. 858] Polyhydroxybutyrate (or poly- (R) -3-hydroxybutyrate, PHB) is the first PHA polymer discovered which has already been studied well. Today more than 150 monomeric structures in PHA have been registered. Such a variety of monomeric structures provides a wide range of physicochemical properties of the obtained polymers, ranging from brittle to flexible, elastic and adhesive PHA [2, p. 893]. In the PHA biosynthesis, the structure of the monomer in the composition of the PHA polymer is 
determined by the specificity of the PHA polymerase (or PHA-synthase) to the monomers incorporated into the polymer. Since the biosynthesis of PHA is carried out by microorganisms in an water environment containing stable resources, such as starch, glucose, sucrose, fatty acids or even nutrient compounds from wastewater, this process is therefore environmentally friendly and sustainable, especially in conditions of depletion of an irrational resource such as oil. The development of PHA production makes it possible to solve at least three problems in the chemical industry: saving petroleum products for the production of plastic materials, reducing $\mathrm{CO} 2$ emissions and protecting the environment. All these factors are important requirements for sustainable development in the chemical and construction materials industries.

One of the main problems of widespread industrial use of PHA is the cost of carbon substrates for the growth of microorganisms, which is estimated at $28-50 \%$ of the total production process [3, p. 546]. There are a number of complex types of waste that can potentially be used as carbon substrates in the production of microbial PHA such as municipal wastewater, agricultural waste, synthesis gas production waste and traditional plastic waste.

Food production waste is the main candidate for an inexpensive carbon source for the growth of microorganisms of PHA producers. A global problem is the utilization of food waste that is generated at different stages in food production systems from the receipt of food products and packaging up to the disposal of substandard products at the end of their shelf life. Another important factor that is associated with the utilization of food waste is the energy spent on the production, processing and transportation of waste. If alternative technologies have been developed to transform food waste into value-added products, then energy is essentially converted into useful products. The conversion of food waste into value-added products has attracted great attention due to the creation of a wide range of production technologies such as biopolymers, biofuels, materials and various additional chemical compounds.

There are many different approaches proposed for converting food waste into PHA. They are based on the use of the many types of waste generated in the production, processing and use of food products. Each type of food waste has its own difficulties and requires various preliminary treatments, selection of bacteria strains, selection of cultivation conditions and the subsequent process of isolation and purification. Organic compounds in food waste can often be complex compounds that cannot be directly used by PHAproducing microorganisms. In these cases pre-treatment is required to convert complex molecules in the food waste into PHA precursors. This is primarily simple sugars (glucose or lactose), fatty acids (acetic or propionic acids). Many simpler food wastes do not require pre-treatment but they are directly used by microorganisms during microbiological synthesis. Biotechnological methods for such wastes as whey, starch, oils, lignocellulosic materials, legumes and sugar wastes have been proposed for their use in the synthesis of PHA.

Over the past few decades the production of PHA by various microorganisms has improved significantly thanks to process optimization and metabolic engineering. Recently the use of systematic analysis of metabolic, signaling and regulatory networks has made it possible to comprehensively understand the global physiology of cells that accumulate PHA. Using this systematization of biological research and computer technology, new directions and strategies can be developed to improve the production 
of PHA with the subsequent construction of a new metabolic system for new PHA with the desired composition of monomers and molecular weight.

The constructed strains should be further modified to obtain PHA to a sufficiently high intracellular concentration with high productivity using a cheap carbon source. The use of systemic biotechnology to develop a scheme for the production of PHA makes it possible to produce polymers efficiently and economically competitively that can replace polymers derived from oil products. A successful result depends on the competent conduct of metabolic engineering, which subsequently allows us to present the optimal integrated analysis for carrying out industrial processes at different stages of production.

\section{The Current State of PHA Production}

\section{PHA from Sugar Industry Waste}

Several types of sugar industry waste have been investigated as potential substrates in the production of PHA. One of them is low-grade molasses produced in sugar factories. It is a residual syrup with a high sucrose content but not suitable for food. Chaudhry et al. used bacteria of the genus Pseudomonas for processing sugar industry waste in PHA and

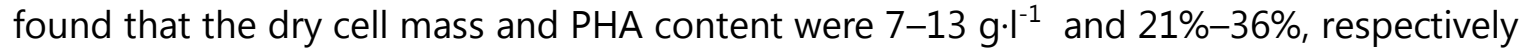
$[4$, p. 626].

Sugar beets are another high-sucrose industrial waste. The strain Alcaligenes latus (ATCC 29714) cultivated under optimal conditions on sugar beet juice and supplemented with nutrients, reached a dry cell content of $10.3 \mathrm{~g} \cdot \mathrm{I}^{-1}$ and with a PHB content of $38.7 \%$ [5, p. 802]. The Italian company Bio-on has also developed a number of PHA polymers using sugar beet juice $[6$, p. 62]. Currently the company uses sugar beet and sugar cane processing waste supplied from all over the world for the production of PHA with the subsequent use of the polymer in cosmetics and pharmaceuticals.

Bagassa is the lignocellulosic residue after processing sugar beets or sugar cane. It was considered as a source of xylose for the production of PHA [7, p. 3]. Bagasse requires pre-treatment to produce digestible sugars and remove inhibitory compounds such as formic acid, acetic acid and furfural. Lopes et al. [8, p. 1353] obtained $3.2 \mathrm{~g}^{-1}{ }^{-1}$ of PHB at cultivation of Burkholderia sp. on the sugar cane hydrolyzate after acid treatment at $120^{\circ} \mathrm{C}$. In addition, PHBV was obtained by adding levulinic acid. Yu and Stahl also showed C. necator growth on sugarcane pulp after acid treatment and heating. In order to avoid the inhibitory effect of the hydrolyzate obtained, a large volume of the inoculum of the tolerant strain of $C$. necator was used. It ultimately produced PHB up to $57 \%$ by weight of dry cells [9, p. 8046]. Thus, bagasse can not only be used in the traditional way as fuel for boilers or as raw material for paper but also as a carbon source for the production of PHA.

Vinassa (acid compost with a pH of 3.5-5.0 and a high content of organic substances) is another important waste of the sugar industry. Recent studies have shown the use of vinassa as a carbon source for the production of PHA by halophilic archaea, such as Haloarcula marismortui and $\mathrm{H}$. mediterranei [10]. The main advantage of these bacteria is their undemanding use of a sterile medium due to the high salinity of the culture medium, as well as the ability to produce PHBV without the addition of organic acids as precursors. In this case, the main disadvantage of the technological application of halophilic organisms is the need for saline utilization after fermentation. In addition 
vinassa contains polyphenolic inhibitory compounds. Their removal requires preliminary treatment, for example, adsorption on activated carbon [10, p. 1].

\section{PHA from Whey}

Whey is one of the common types of food waste. It is of interest for the biosynthesis of PHA. Whey is a by-product of the cheese production process. It contains lactose, proteins, fats, water-soluble vitamins, mineral salts and other essential nutrients necessary for the growth of microorganisms. Although whey itself is used as a raw material for the production of lactose, casein and protein powder, it is estimated that approximately $50 \%$ of whey is utilized through a wastewater system or used as animal feed [11, p. 6183]. The lactose-enriched retentate remains as a waste that must be disposed of when using whey to produce proteins such as lactoferrin or lactoferricin. In addition acid whey is a by-product of the production of cottage cheese, cream cheese and yogurt. While acidic whey can be used as bio-feed, traditional whey protein is difficult to process due to its high acid content [12, p. 483]. The dairy industry faces an acute problem such as whey utilization. Its solution makes it possible to get a potentially inexpensive source of carbon in the production of PHA [13, p. 39]. In addition whey has another advantage. It does not require pre-treatment using enzymatic or acid methods for subsequent use in cultivation processes. The main limitation in the production of PHA from whey is the energy requirement for the fermentation process and the low level of PHA yield per kg of whey.

Recently recombinant E. coli strains have been used for microbiological synthesis of PHA using whey, since many microorganisms producing PHA cannot directly metabolize whey.

\section{PHA from Starch}

Starch is another carbon source that has been studied as a substrate for the microbiological PHA production. Starch is a polymer of glucose found in plants such as rice, wheat, potatoes, corn and cassava. Despite the fact that starch is consumed by people, there are significant flows of starchy waste from food production which can be used by microorganisms producing PHA. Strain Cupriavidus sp. KKU38 was isolated from wastewater in the production of starch from cassava in the work of Poomipuk et al. It was used in the biosynthesis of PHA [14, p. 53]. This study showed that Cupriavidus sp. produces a relatively high biomass concentration of $6.0 \mathrm{~g} \cdot \mathrm{I}^{-1}$ with a PHA content of $62 \%$ under optimal cultivation conditions with nitrogen starvation.

Kim [15, p. 774] used the Azotobacter croococcum strain as a PHA producer and ruled out the use of expensive enzymes for starch hydrolysis since this type of bacteria itself can directly utilize starch. In this work the author performed cultivation under conditions of oxygen starvation and obtained $54 \mathrm{~g} \cdot \mathrm{l}^{-1}$ of dry cell biomass with a PHB content of $46 \%$. This study has demonstrated the possibility of obtaining high concentrations of cells containing PHA using starchy food waste.

\section{PHA from Used Oil}

Used oils for both domestic and industrial use are potential carbon sources for the production of PHA. These oils usually do not require pretreatment and can be added directly to the carrier as a carbon substrate. Taniguchi et al. investigated the use of Cupriavidus necator $\mathrm{H} 16$ for the processing of used oil and fat in PHA [16, p. 545]. The 
greatest amount of PHA was obtained with the growth of bacteria in palm oil and fat. The weight of dry cells was $\left.6.8 \mathrm{~g}^{-1}\right|^{-1}$ with the accumulation of $\mathrm{PHB}-83 \%$. It was also shown in this work that a copolymer was synthesized - poly- (3-hydroxybutyrate-3hydroxyvalerate) (PHBV) instead of pure PHB in the process of using fat as a carbon source.

Obruca et al. used waste of rapeseed oil, palm oil and sunflower oil as carbon sources in the synthesis of PHA by this bacterium C. necator H16 [17, p. 2426]. The weight of dry cells $\left(\mathrm{g} \cdot \mathrm{I}^{-1}\right)$ and the PHB content (\%) were 10.8 and $68 \%, 12.0$ and $58 \%$, and 10.8 and $52 \%$, respectively, for different types of oil. Strain Pseudomonas sp. gave a dry cell weight of $12.5 \mathrm{~g}^{-1}{ }^{-1}$ with a mcl-PHA content of $36 \%$ [4, p. 626] when growing on used corn oil. Bacteria of the Pseudomonas species accumulated less PHA in the cells compared with C. necator H16. However, the synthesized mcl-PHA was a more desirable biosynthesis product than PHB. The monomer in the composition of mcl-PHA has a large length which improves the physico-chemical characteristics of the resulted polymer. These studies show that using used oils as a carbon source allows cells to accumulate high concentrations of PHA.

\section{Processing of Lignocellulosic Waste in PHA}

Lignocellulosic materials are compounds of plant origin that are complex in structure. They consist of cellulose, pectin, hemicellulose and lignin. Examples of this type of waste in the food industry are wheat straw, bran, bagasse and rice straw. As a rule, waste from lignocellulosic compounds requires hydrolysis to turn them into fermentable sugars and then detoxification to remove the inhibitory compounds formed during hydrolysis. Various lignocellulosic materials were studied for the biosynthesis of PHA, including waste from palm oil production [9, p. 307], wheat and rice straw [18, p. 104], bagasse (sugarcane waste) [19, p. 8043]. Early work showed that despite pretreatment, lignocellulosic materials produced low biomass accumulation. However, one of the most promising lignocellulosic processes was investigated by Cesario et al. [18, p. 105]. The AFEX process (destruction of cellulose by ammonia) followed by enzymatic hydrolysis of cellulose and hemicellulose fractions to produce glucose, xylose and arabinose was used in this study as a preliminary treatment of cellulose from crushed wheat straw. Burkholderia sacchari DSM 17165 was cultured on this hydrolyzate in a batch culture regime with recharge. As a result, the biomass concentration was $146 \mathrm{~g}^{\cdot l^{-1}}$ and the PHA concentration was $72 \%$. Despite the fact that lignocellulosic materials, as a rule, require complex preliminary processing, they represent a certain potential as carbon substrates.

\section{The Synthesis of PHA by Mixed Cultures}

Production of PHA by mixed cultures with growth in wastewater has shown high financial efficiency in comparison with the production of PHA by pure crops. Since financial and environmental costs were mainly associated with the use of energy for the subsequent purification of the obtained polymer, there is great potential for optimization PHA production in this process. Thus, biotechnology of a mixed culture can become an attractive addition or alternative to traditional biotechnology based on the use of pure crops in the production of PHA, other chemicals, or bioenergy.

PHA can be obtained by mixed cultures if a suitable enrichment step is used. A batch reactor (Sequential Batch Reactor, SBR) operating in the regime with a daily biomass 
residence time and with 12-hour recharge cycles was used for enriching a mixed culture of PHA producers during this cultivation [20, p. 671]. The enriched mixed culture produced $89 \%$ of PHA on the wet weight of the cells for 8 hours in subsequent experiments with feeding under conditions of growth restriction. Gammaproteobacteria dominated in the mixed culture. The mixed cultivation process for the production of PHA does not require aseptic conditions. Wastewater rather than pure substrates can be used as raw material. Such an open and continuous process is very important for saving energy used to maintain sterile conditions in the fermentation process.

Thus, the use of wastewater from food and agricultural enterprises in the biosynthesis of PHA by mixed bacterial cultures can ultimately significantly reduce the cost of PHA production.

\section{Recombinant Microorganisms in the Synthesis of PHA}

At the moment, natural strains of microorganisms are most often used in the conversion of carbon substrates based on food waste into PHA. The use of recombinant microorganisms may be more effective in the synthesis of a biopolymer, since cultivation can occur without stimulation of stressful conditions such as nitrogen or phosphorus starvation, which may result in a decrease in the cost of the process. In addition recombinant microorganisms are studied well and thus they can be further optimized by engineering the recombinant strain.

It is known that recombinant bacterial strains can grow on substrates on which natural strains producing PHA cannot be cultured. Moreover, the cultivation of recombinant microorganisms increases the growth rate of biomass and, accordingly, the accumulation of PHA. This can significantly affect the cost of polymer synthesis.

E. coli is a model organism used in genetic engineering. As it has been shown it is a beneficial object in the production of PHA. Some E. coli strains are capable of utilizing lactose, a substrate that many PHA-producing organisms such as $\mathrm{C}$. necator do not metabolize. Thus, many studies have been performed using high-lactose whey as a carbon source for culturing recombinant E. coli with PHA-producing genes (pha-operon) from C. necator.

The first studies using recombinant $\mathrm{E}$. coli showed the potential of this technique. The subsequent studies were aimed at improving yield and product quality. The studies improved these methods by monitoring the time of PHA biosynthesis in recombinant $\mathrm{E}$. coli using lactose. These and other studies encountered one common problem such as the relatively low solubility of lactose in water and the relatively low productivity of PHA. Ahn et al. [21, p. 3626] optimized the cultivation processes in the bioreactor in a subsequent study. This led to the achievement of the final cell concentration and PHB content of $110 \mathrm{~g} \mathrm{I}^{-1}$ and $87 \%$, respectively.

Two other studies used recombinant E. coli to obtain PHA from whey. Pais et al. investigated recombinant strains of $\mathrm{E}$. coli with a low level of biosynthesis of organic acids and transformed these strains with a pha-operon from C. necator [22, p. 152]. The results showed that a decrease in the biosynthesis of organic acids led to a slower growth but at the same time increased the synthesis of PHB (19 g.l. initial transformed strain). Another study used a recombinant E. coli F8 strain carrying the genes for PHB biosynthesis from Azotobacter sp. for the production of PHB from whey 
and corn liquor as the main source of carbon and nitrogen. The maximum cell density

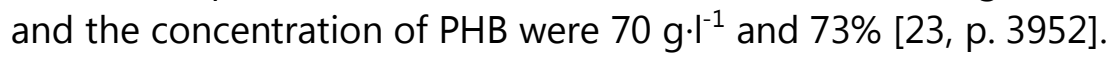

Another recombinant strain of Aeromonas sp. (strain KC007-1) was used in addition to E. coli. The strain was chosen for its ability to directly use starch as a carbon source, while the PHA-operon from $\mathrm{C}$. necator $\mathrm{H} 16$ was additionally transformed into cells in order to increase the yield of PHA. Ultimately, bacteria were able to accumulate up to $33 \%$ of PHA [24].

\section{Conclusions}

The use of food waste in obtaining PHA is a promising direction having some difficulties. The main difficulty is the reduction in the cost of production of microbial PHA. In this regard, the optimization of food waste utilization processes and their pre-treatment should be studied as thoroughly as possible in order to achieve a reduction in overall production costs. Ideally, pre-treatment of food waste should be minimized to reduce not only cost but also process time. It is also necessary to take into account the cost of the separation and purification of PHA in the feasibility study. In addition, the concept of using bioprocessing of food waste can be implemented not only in the production of one PHA as a target product but also in the production of other additional compounds.

As it has been already mentioned, the natural producers of PHA, as well as genetically modified strains of microorganisms, can be used as platforms for the production of PHA. The choice of strain is an important aspect and the search for new strains may lead to the discovery of additional microorganisms that can be used as production strains of PHA in the future.

Food losses are a global problem. The possibility of implementing technological projects to modify complex carbon substrates into material products such as PHA will reduce the environmental burden on both large cities and the environment as a whole. As shown in the review, there are many approaches to the processing of food waste in PHA. However, there is no single solution for the use of a certain type of food waste. The choice of the path along which the technological solution for the production of PHA will be implemented depends on many factors that must be taken into account. Each path has its own advantages and disadvantages. Undoubtedly, new innovative methods of processing food waste in PHA will continue to develop. These new technologies can make the economic production of microbial PHA effective in the near future.

\section{Acknowledgments}

This work was carried out as part of basic budget financing (Project No. 0585-20190044).

\section{References}

(1) Obruca, S.; Sedlacek, P.; Koller, M.; Kucera, D.; Pernicova, I. Involvement of Polyhydroxyalkanoates in Stress Resistance of Microbial Cells: Biotechnological Consequences and Applications. Biotechnology Advances 2018, 36 (3), 856-870. https://doi.org/10.1016/j.biotechadv.2017.12.006. 
(2) Bugnicourt, E.; Cinelli, P.; Lazzeri, A.; Alvarez, V. The Main Characteristics, Properties, Improvements, and Market Data of Polyhydroxyalkanoates. In Handbook of Sustainable Polymers: Processing and Applications; Thakur, V., Thakur, M., Eds.; Jenny Stanford Publishing: New York, 2015; pp 899-928. https://doi.org/10.1201/b19600.

(3) Strong, P.; Laycock, B.; Mahamud, S.; Jensen, P.; Lant, P.; Tyson, G.; Pratt, S. The Opportunity for High-Performance Biomaterials from Methane. Microorganisms 2016, 4 (1), 11. https://doi.org/10.3390/microorganisms4010011.

(4) Chaudhry, W. N.; Jamil, N.; Ali, I.; Ayaz, M. H.; Hasnain, S. Screening for Polyhydroxyalkanoate (PHA)-Producing Bacterial Strains and Comparison of PHA Production from Various Inexpensive Carbon Sources. Annals of Microbiology 2011, 61 (3), 623-629. https://doi.org/10.1007/s13213-010-0181-6.

(5) Wang, B.; Sharma-Shivappa, R. R.; Olson, J. W.; Khan, S. A. Production of Polyhydroxybutyrate (PHB) by Alcaligenes Latus Using Sugarbeet Juice. Industrial Crops and Products 2013, 43, 802-811. https://doi.org/10.1016/j.indcrop.2012.08.011.

(6) Dietrich, K.; Dumont, M.-J.; Del Rio, L. F.; Orsat, V. Producing PHAs in the Bioeconomy - Towards a Sustainable Bioplastic. Sustainable Production and Consumption 2017, 9, 58-70. https://doi.org/10.1016/j.spc.2016.09.001.

(7) Silva, L. F.; Taciro, M. K.; Raicher, G.; Piccoli, R. A. M.; Mendonça, T. T.; Lopes, M. S. G.; Gomez, J. G. C. Perspectives on the Production of Polyhydroxyalkanoates in Biorefineries Associated with the Production of Sugar and Ethanol. International Journal of Biological Macromolecules 2014, 71, 2-7. https://doi.org/10.1016/j.ijbiomac.2014.06.065.

(8) Lopes, M. S. G.; Gomez, J. G. C.; Taciro, M. K.; Mendonça, T. T.; Silva, L. F. Polyhydroxyalkanoate Biosynthesis and Simultaneous Remotion of Organic Inhibitors from Sugarcane Bagasse Hydrolysate by Burkholderia Sp. Journal of Industrial Microbiology \& Biotechnology 2014, 41 (9), 1353-1363. https://doi.org/10.1007/s10295-014-1485-5.

(9) Zhang, Y.; Sun, W.; Wang, H.; Geng, A. Polyhydroxybutyrate Production from Oil Palm Empty Fruit Bunch Using Bacillus Megaterium R11. Bioresource Technology 2013, 147, 307-314. https://doi.org/10.1016/j.biortech.2013.08.029.

(10) Bhattacharyya, A.; Pramanik, A.; Maji, S.; Haldar, S.; Mukhopadhyay, U.; Mukherjee, J. Utilization of Vinasse for Production of Poly-3-(Hydroxybutyrate-CoHydroxyvalerate) by Haloferax Mediterranei. AMB Express 2012, 2 (1), 2-34. https://doi.org/10.1186/2191-0855-2-34.

(11) Pescuma, M.; de Valdez, G. F.; Mozzi, F. Whey-Derived Valuable Products Obtained by Microbial Fermentation. Applied Microbiology and Biotechnology 2015, 99 (15), 6183-6196. https://doi.org/10.1007/s00253-015-6766-z.

(12) Ryan, M. P.; Walsh, G. The Biotechnological Potential of Whey. Reviews in Environmental Science and Bio/Technology 2016, 15 (3), 479-498. https://doi.org/10.1007/s11157-016-9402-1. 
(13) Girotto, F.; Alibardi, L.; Cossu, R. Food Waste Generation and Industrial Uses: A Review. Waste Management 2015, 45, 32-41. https://doi.org/10.1016/j.wasman.2015.06.008.

(14) Poomipuk, N.; Reungsang, A.; Plangklang, P. Poly- $\beta$-Hydroxyalkanoates Production from Cassava Starch Hydrolysate by Cupriavidus Sp. KKU38. International Journal of Biological Macromolecules 2014, 65, 51-64. https://doi.org/10.1016/j.ijbiomac.2014.01.002.

(15) Kim, B. S. Production of Poly(3-Hydroxybutyrate) from Inexpensive Substrates. Enzyme and Microbial Technology 2000, 27 (10), 774-777. https://doi.org/10.1016/S0141-0229(00)00299-4.

(16) Taniguchi, I.; Kagotani, K.; Kimura, Y. Microbial Production of Poly(Hydroxyalkanoate)s from Waste Edible Oils. Green Chemistry 2003, 5 (5), 545548. https://doi.org/10.1039/B304800B.

(17) Obruca, S.; Snajdar, O.; Svoboda, Z.; Marova, I. Application of Random Mutagenesis to Enhance the Production of Polyhydroxyalkanoates by Cupriavidus Necator H16 on Waste Frying Oil. World Journal of Microbiology and Biotechnology 2013, 29 (12), 2417-2428. https://doi.org/10.1007/s11274-013-1410-5.

(18) Cesário, M. T.; Raposo, R. S.; de Almeida, M. C. M. D.; van Keulen, F.; Ferreira, B. S.; da Fonseca, M. M. R. Enhanced Bioproduction of Poly-3-Hydroxybutyrate from Wheat Straw Lignocellulosic Hydrolysates. New Biotechnology 2014, 31 (1), 104113. https://doi.org/10.1016/j.nbt.2013.10.004.

(19) Yu, J.; Stahl, H. Microbial Utilization and Biopolyester Synthesis of Bagasse Hydrolysates. Bioresource Technology 2008, 99 (17), 8042-8048. https://doi.org/10.1016/j.biortech.2008.03.071.

(20) Johnson, K.; Jiang, Y.; Kleerebezem, R.; Muyzer, G.; van Loosdrecht, M. C. M. Enrichment of a Mixed Bacterial Culture with a High Polyhydroxyalkanoate Storage Capacity. Biomacromolecules 2009, 10 (4), 670-676. https://doi.org/10.1021/bm8013796.

(21) Ahn, W. S.; Park, S. J.; Lee, S. Y. Production of Poly(3-Hydroxybutyrate) By FedBatch Culture of Recombinant Escherichia Coli with a Highly Concentrated Whey Solution. Applied and Environmental Microbiology 2000, 66 (8), 3624-3627. https://doi.org/10.1128/AEM.66.8.3624-3627.2000.

(22) Pais, J.; Farinha, I.; Freitas, F.; Serafim, L. S.; Martínez, V.; Martínez, J. C.; ArévaloRodríguez, M.; Auxiliadora Prieto, M.; Reis, M. A. M. Improvement on the Yield of Polyhydroxyalkanotes Production from Cheese Whey by a Recombinant Escherichia Coli Strain Using the Proton Suicide Methodology. Enzyme and Microbial Technology 2014, 55, 151-158. https://doi.org/10.1016/j.enzmictec.2013.11.004.

(23) Nikel, P. I.; de Almeida, A.; Melillo, E. C.; Galvagno, M. A.; Pettinari, M. J. New Recombinant Escherichia Coli Strain Tailored for the Production of Poly(3Hydroxybutyrate) from Agroindustrial By-Products. Applied and Environmental Microbiology 2006, 72 (6), 3949-3954. https://doi.org/10.1128/AEM.00044-06. 
(24) Chien, C.-C.; Ho, L.-Y. Polyhydroxyalkanoates Production from Carbohydrates by a Genetic Recombinant Aeromonas Sp. Letters in Applied Microbiology 2008, 47 (6), 587-593. https://doi.org/10.1111/j.1472-765X.2008.02471.x.

\section{Information about Authors}

Sergey Mikhailovich SHISHLYANNIKOV: Ph.D. in Biology, Senior Researcher, All-Russian Research Institute of Food Additives - Branch of Federal Scientific Center for Food Systems of Russian Academy of Sciences named after V.M. Gorbatov; 55 Liteyny Ave., St. Petersburg, 191014, Russia; e-mail: sershilin@gmail.com.

Veniamin Yurevich SITNOV: Ph.D. in Biology, Director of All-Russian Research Institute of Food Additives - Branch of Federal Scientific Center for Food Systems of Russian Academy of Sciences named after V.M. Gorbatov; 55 Liteyny Ave., St. Petersburg, 191014, Russia; e-mail: v.sitnov@fncps.ru. 